\title{
Article \\ A Longitudinal Look at Family Communication about Sexual Issues
}

\author{
Jennifer M. Grossman * (D) and Amanda M. Richer
}

check for

updates

Citation: Grossman, J.M.; Richer,

A.M. A Longitudinal Look at Family Communication about Sexual Issues. Sexes 2022, 3, 164-177. https:// doi.org/10.3390/sexes3010013

Academic Editor: David L. Rowland

Received: 23 December 2021

Accepted: 18 February 2022

Published: 23 February 2022

Publisher's Note: MDPI stays neutral with regard to jurisdictional claims in published maps and institutional affiliations.

Copyright: (c) 2022 by the authors. Licensee MDPI, Basel, Switzerland. This article is an open access article distributed under the terms and conditions of the Creative Commons Attribution (CC BY) license (https:/ / creativecommons.org/licenses/by/ $4.0 /)$.

\begin{abstract}
Wellesley Centers for Women, Wellesley College, Wellesley, MA 02481, USA; aricher@wellesley.edu * Correspondence: jgrossma@wellesley.edu
\end{abstract}

\begin{abstract}
Parent-child communication about sex and relationships can protect adolescents from risky sexual behaviors, but few studies investigate how family talk may change over the course of development from adolescence to emerging adulthood. This current study uses thematic analysis to explore continuity and change in perceived talk with parents about sex and relationships, following a United States sample of 15 adolescent participants over three time points: early adolescence (age 13-14), middle adolescence (age 15-16), and emerging adulthood (age 20-21). Analyses addressed participants' experiences of talk with parents about sex and relationships (comfort, engagement) and the content of talk: dating and relationships, pregnancy and parenting, protection, STIs, and sexual behavior. Findings show that family communication about sex and relationships extends from early adolescence to emerging adulthood, but changes in content to reflect shifts in adolescent and emerging adult development. Further, while positive engagement and comfort with talk about sex remain relatively high over time, participants' discomfort and negative engagement appear to increase, highlighting challenges for ongoing family communication. These findings suggest a meaningful, ongoing role for parents in family communication about sex and relationships as their children develop, and suggest some opportunities and challenges that parents may face through this process.
\end{abstract}

Keywords: family communication; parent-child relationships; talk about sex; adolescence; emerging adulthood; qualitative; longitudinal

\section{Introduction}

Talk with parents about sex can protect early (10-13 years old) and middle (14-17 years old) adolescents from risky sexual behaviors and is associated with delayed sex and use of protection among sexually active teens [1,2]. Initial studies suggest that the protective effects of family talk about sex during adolescence may extend into emerging adulthood [3,4], but few studies assess family talk about sex during this period. Emerging adulthood is a developmental period from ages 18 to 25 , categorized as in-between adolescence and full-fledged adulthood, proposed by Jeffrey Arnett, a developmental psychologist in the U.S. [3-5]. Each stage of adolescence and emerging adulthood is characterized by unique developmental tasks and challenges related to relationships and sex [6]. In addition, relationships with parents change over the course of development. From early to middle adolescence, youth shift toward growing independence, often accompanied by increased separation from parents, while new opportunities for connection and mutuality with parents arise as adolescents move toward adulthood [7]. Pivotal changes in young people's engagement with romantic relationships and sex and with parental relationships during adolescence and emerging adulthood highlight the need to understand family communication about sex and relationships in a dynamic way. However, few studies longitudinally assess adolescents' talk with their parents and no studies qualitatively investigate family talk about sex from early adolescence to emerging adulthood. The current study provides a unique longitudinal qualitative exploration of young people's perceptions of communication with their parents about sex and relationships from early adolescence to middle adolescence to emerging adulthood. 
Early adolescence is a developmental stage when teens often begin to explore dating and relationships [6]. Middle adolescence typically involves increased engagement in romantic relationships and sexual activity. Emerging adulthood (age 18-25) is often characterized by exploration of intimacy and sexuality [5]. This developmental stage is marked by particularly high levels of sexual risk, including higher risk of sexually transmitted infections (STIs) and unplanned pregnancies [8,9], due to high rates of casual sex [10] and higher numbers of sexual partners [11] than other age groups.

Family talk about sex and relationships occurs (or is absent) in the context of parentchild relationships as a whole, which shift and grow from early to middle adolescence and into emerging adulthood. Theorists describe interplay between individuality and attachment, which involves interactive dynamics of teens' growing separation from parents as well as the development of mutuality and connection with them [7]. Early adolescence is a time with high parental authority and increasing teen separation from parents. These trends continue to develop during middle adolescence, with increasing independence from parents [7]. In a shift from adolescence, emerging adulthood entails new opportunities for mutuality and connection with parents [12]. With growing differentiation from parents during emerging adulthood, young people often develop less hierarchical relationships with parents [13] and increased openness in family communication [14].

These shifts in parent-child relationships are also reflected in how young people talk with their parents about sex and relationships. Early adolescents may be relatively comfortable talking with parents about sex, but as adolescents become sexually active, they often report increasing avoidance and discomfort in talking with parents about sex, often tied to concerns about parents' negative judgements about their behaviors or not wanting their parents to worry about them $[15,16]$. This is also consistent with shifts toward increasing autonomy and desire for privacy later in adolescence. For example, interviews with parents of participants in the current study showed that parents viewed their teens as responding more negatively to talk with parents about sex during middle adolescence than in early adolescence [17]. Further, conversations with parents about sex can be more in-depth and focused on a specific relationship during emerging adulthood than those in early or middle adolescence [18]. In contrast, a longitudinal quantitative study of adolescents' reported talk with their parents about sex showed stable levels of communication from age 14 to 18 [19], although the range of topics was limited and the quality of conversations was not assessed. A qualitative study found that from the first to the last year of college, emerging adults' described talk with parents about sex as becoming more open and reciprocal over time [14]. Cross-sectional studies with emerging adults suggest similar patterns, such as a study which found college students reported a wish to talk more frequently and openly with parents about sexual issues [20], representing a change from adolescence.

Gender plays a key role during adolescence in whether parents talk with their teens and the content of their communication [2,21,22]. Specifically, mothers are more likely than fathers to talk with teens about sex and parents are more likely to talk with their female than male teens about sexual topics. The content of parents' talk with teens often includes gender-based norms and expectations, such as messages to girls about delaying sex and resisting boys' advances $[23,24]$. For example, a recent study found that mothers had a greater likelihood of talking with their daughters about sexual risk than sex-positive topics compared to other groups (i.e., fathers and sons, fathers and daughters, mothers and sons) [25]. However, few studies assess the role of gender in parents' talk with their emerging adult children about sex, or continuity and change in the role of gender over the course of adolescent and emerging adult development. A recent study of parents found that while the content of talk with male and female teens was relatively consistent over time, parents were more likely to describe talk with boys than girls about sexual behavior from early adolescence to emerging adulthood and to describe a lack of readiness as a reason not to talk with early adolescent girls about sex [18]. These patterns fit with traditional 
gendered approaches to talk with sons and daughters about sex [26], which may persist over the course of development.

Investigation of how adolescents view talk with parents about sex and relationships over the course of development is needed to better understand what types of communication with parents works for young people at different stages of development. This study can suggest ways parents can adapt their approaches to talking with their children to match their developmental stage regarding both sex and relationships and connections with parents. The current paper explores participants' perceptions and content of talk with parents about sex and relationships over time and the role of teen and emerging adult gender in these conversations in a U.S. sample. This is the first qualitative study to investigate young people's perspectives on parent-child talk about sex and relationships over three stages of development: early adolescence, middle adolescence, and emerging adulthood.

\section{Materials and Methods}

\subsection{Recruitment and Participants}

This longitudinal interview sample includes adolescents recruited from three schools who were part of an evaluation of a sex education program when the participants were in middle school. The students participated in the school-based program, Get Real: Comprehensive Sex Education That Works, developed by Planned Parenthood League of Massachusetts. Researchers interviewed 15 participating teens at three time points: when the teen was in 7th grade (Time 1, age = 13-14 years old), when the teen was in 10th grade (Time 2, age $=15-16$ years old), and after high school (Time 3 , age $=21-22$ years old) [27]. For teens who completed Time 1 and Time 2 interviews, teens were contacted four years later by phone, text or email and invited to participate in an additional interview. Parental consent was required at Time 1 and Time 2. At Time 3, all participants were over 18 years old and therefore provided their own active consent. Of the original 29 teens interviewed at Time 1, 17 teens completed the interview at Time 3, eight teens were unreachable, and four teens declined to participate. The analysis sample for this paper only includes the 15 teens who completed interviews at all three waves. The sample is small, but it is similar to other longitudinal qualitative investigations [28].

Time 1 interviews were completed in person and Time 2 and Time 3 interviews were completed over the phone. Fourteen participants completed interviews in English, and one teen completed an interview in Spanish. Interviews took about $30 \mathrm{~min}$. They were then translated, as needed, and transcribed. Participants were given $\$ 25$ at Time 1 and Time 2, and $\$ 40$ at Time 3 in appreciation of their participation. The interviewers asked each participant to make up a code name to safeguard their confidentiality; those code names are used in this paper. Interviewers gave each participant a resource list with organizations supporting youth and family social, emotional, and sexual health. Human subjects' approval was granted from The Institutional Review Board at Wellesley College to conduct this research (January 2011, December 2013, August 2018).

The current sample includes seven male teens and eight female teens. Over half $(n=8)$ of teens self-identified as Black/African American (53\%), three identified as White/Caucasian $(20 \%)$, three identified as Hispanic $(20 \%)$, and one teen identified as Multiracial $(7 \%)$. At Time 3, participants described their current status as either working $(40 \%, n=6)$ in jobs such as food service and retail, or in college $(60 \%, n=9)$, which included trade school and four-year colleges. At Time 1, 43\% $(n=6)$ of students reported rarely talking to their parent about dating, relationships and sex, $43 \%(n=6)$ reported sometimes talking, and $14 \%(n=2)$ reported talking often. At Time 2, 31\% $(n=4)$ of students reported rarely talking to parents, $61 \%(n=8)$ reported talking sometimes and $8 \%(n=1)$ reported talking often. At Time 3 , $27 \%(n=4)$ reported talking to parents rarely, $40 \%(n=6)$ reported talking sometimes and $33 \%(n=5)$ reported talking often. 


\subsection{Interview Protocol and Procedures}

Before starting the interviews, participants were reminded of the purpose of the study and told that they might feel embarrassed or uncomfortable, and that they could choose not to answer any questions. Interviews were semi-structured and included similar questions at each time point, addressing the content of communication with their parents, their comfort with this communication, and their understanding and experiences of talking with their parents about sexual issues. To address content of communication, interviewers said, "I'm going ask you about some things that families sometimes talk about. For each one, will you tell me whether you've talked about this topic with [your mother/father]? Then, I'll ask you to try to remember a conversation you had about each topic". To explore participants' experiences and perceptions, interviewers made follow-up comments such as such as "tell me more about that" and "what do you think about that". To assess comfort, interviewers asked participants, "How comfortable are you talking about sex and relationships with [your mother/father]? What do you think makes it [comfortable/uncomfortable] for you to talk with [your mother/father] about sex and relationships?" Time 2 and Time 3 interviews included questions about any change over time in talk with their parents about sex and relationships. Interviewers included the PI and additional interviewers. The PI trained all interviewers to understand the protocol and sample. To minimize social desirability related to interviewing participants over multiple time points, the research team discussed bias in interview training.

\subsection{Data Analysis}

Themes in the interviews were identified through a content analysis approach [29]. The investigators identified overarching themes, then discussed and revised them. Next, the investigators looked for further examples in other interviews. The authors assessed how participants talked with their parents about sex and relationships and how they approached these conversations across the three time points. The authors conducted reliability checks for their qualitative coding, with reliability equaling the number of agreements divided by the total number of codes [30]. They coded data from five participants at a time and discussed coding disagreements. The final intercoder reliability was $90 \%$, showing a high level of coder agreement. The themes were not mutually exclusive, such that a participant's response could be coded with more than one theme. NVivo 10.0 [31] was used for qualitative coding.

\section{Results}

The first two themes reflect teens'/emerging adults' experiences with talk about sex and relationships with their parents: comfort (and discomfort) talking with parents and engagement with talk with parents about sex and relationships. The remaining 5 themes focus on content areas related to talk with parents about sex and relationships, including: talk about dating and relationships, talk about pregnancy and parenting, talk about protection, talk about STIs, and talk about sexual behavior. To more clearly show how teen-parent conversations change over time, the results include examples of individual participants ${ }^{\prime}$ interview responses for each time point. Table 1 provides overall percentages for each theme and subtheme across each time point and Table 2 includes comparisons based on the participants' gender.

\subsection{Comfort}

For the comfort theme, participants described how comfortable they feel talking with their parents about sex and relationships and why they feel this way. This theme included two sub themes: comfort and discomfort. 
Table 1. Overall Percentage of Themes across Time Points $(n=15)$.

\begin{tabular}{cccc}
\hline & Time 1 & Time 2 & Time 3 \\
\cline { 2 - 4 } & $\boldsymbol{n}$ & $\boldsymbol{n}$ & $\boldsymbol{n}$ \\
\hline Comfort & & & \\
Comfort & 12 & 13 & 12 \\
Discomfort & 4 & 7 & 10 \\
Engagement with Talk & & 12 & 11 \\
Positive Engagement & 10 & 10 & 9 \\
Negative Engagement & 4 & 11 & 14 \\
Talk about Dating and Relationships & 13 & 12 & 14 \\
Talk about Pregnancy and Parenting & 12 & 12 & 9 \\
Talk about Protection & 9 & 2 & 5 \\
Talk about STIs & 8 & 13 & \\
Talk about Sexual Behavior & 12 & & \\
\hline
\end{tabular}

Table 2. Comparison of Themes by Participant Gender across Time Points.

\begin{tabular}{cccccccc}
\hline & \multicolumn{2}{c}{ Time 1 } & \multicolumn{2}{c}{ Time 2 } & \multicolumn{2}{c}{ Time 3 } \\
\cline { 2 - 7 } & Male & Female & Male & Female & Male & Female \\
\cline { 2 - 7 } & $\boldsymbol{n}$ & $\boldsymbol{n}$ & $\boldsymbol{n}$ & $\boldsymbol{n}$ & $\boldsymbol{n}$ & $\boldsymbol{n}$ \\
\hline Comfort & & & & & & \\
Comfort & 6 & 6 & 5 & 8 & 5 & 7 \\
Engscomfort & 1 & 3 & 3 & 4 & 4 & 6 \\
Positive Engagement & 4 & 6 & 5 & 7 & 5 & 6 \\
Negative Engagement & 1 & 3 & 4 & 6 & 4 & 5 \\
Talk about Dating and Relationships & 7 & 6 & 5 & 6 & 6 & 8 \\
Talk about Pregnancy and Parenting & 6 & 6 & 6 & 6 & 6 & 8 \\
Talk about Protection & 4 & 5 & 6 & 6 & 4 & 7 \\
Talk about STIs & 4 & 4 & 0 & 2 & 4 & 5 \\
Talk about Sexual Behavior & 5 & 7 & 7 & 6 & 2 & 3
\end{tabular}

Note: When comparing responses across gender, please note that there is an unequal number of male (7) and female (8) participants.

Participants' reports of comfort in talking with their parents about sex and relationships was relatively stable across time. At Time 1 and Time 3, 12 participants reported comfort with talk and at Time 2, 13 participants reported comfort with these conversations. However, participants' explanations for why they feel comfortable differed over time. At Time 1, participants described feeling comfortable due to parents providing new information or experiences to conversations about sex and relationships. At Time 2, teens described comfort as related to parents being understanding and not judgmental. At Time 3 , emerging adults reported that their own increase in maturity or experience helped them feel comfortable talking with their parents about sexual issues as well as viewing their parents as trusted sources of information. At Time 1, Brittany described how her mother's experiences helped her feel comfortable, "We're both women and like she's already been through puberty and she's like been through a lot more than I have and she like knows what to do." At Time 2, Brittany mentioned her mother's understanding helped her feel comfortable with these conversations, "She's understanding. Like she understands that I'm going through puberty and I'm a teenager and all that." At Time 3, Brittany described how her own growth and experiences helped her feel comfortable, "I'm definitely more open for conversation when it comes to that stuff, because now that I'm in a relationship like I know what's going on and I know what it's like to be in a relationship." Another teen, Olivia, described her ongoing comfort talking with her mother about sex and relationships. At Time 1 Olivia said, "She's honest and sometimes, most of the time she doesn't go like, "Wait until you're older," at Time 2 she said, "My mom talks to me to like-as a person that I can confide in and it's not like judgmental but she also like gives me advice and stuff 
about it," and at Time 3 she said, "She makes it so that like I don't ever really feel judged and I can randomly stop her in the middle of what she's doing and I can just ask her about this stuff. But I just appreciated that she listened to me and she told me that like she agreed with me and that um-that she's just here for whatever I do."

Participants' reports of discomfort in talking with parents about sex and relationships, on the other hand, tended to increase over time. At Time 1, 4 participants reported discomfort with talk compared to 7 at Time 2 and 10 at Time 3 . At all three time points, participants described feeling embarrassed or awkward talking to parents about sex and relationships. At Time 3, some participants described discomfort with talk about specific topics that felt too personal or might generate conflict. One participant, Sara, talked about her overall discomfort talking with her mother at Time 1, "I'm in the middle. Like I'm not comfortable with my mom, like extremely comfortable," and at Time 2, "It's just constantly talking about it can be kind of weird, especially if you've been-if people act like you're not supposed to talk about that stuff with your mom." At Time 3, she described how her discomfort related to talking about a specific content area, "When it comes to like pregnancy, talking about pregnancy with my mother makes me really uncomfortable, so I don't do it." Another participant, McLovin, explained his discomfort in talking with his mother about sex across all time points. At Time 1, he said "It's kind of weird talking to my mom about sex, and she's talking like back to me. It's kind of weird. Like, it's just weird," at Time 2 he said, "with my mom, the only thing I'm like uncomfortable talking about is sex, because like any time the conversation comes up with her, it's kind of like it makes me feel awkward. But like anybody else really-it could even be like my supervisor at work, I could talk to her about sex. It's like my mom, it just—she makes everything so awkward," and at Time 3 he said, "She like forces it. Like she just goes above and beyond. Like she's very graphic. And I'm just like, 'Ma, stop. Please stop.'“

\subsection{Engagement with Talk}

Engagement with talk refers to participants' participation in or responses to talk with parents about sex and relationships. This theme was divided into two sub themes: positive engagement with talk and negative engagement with talk. Positive engagement with talk includes participants' active participation in a conversation with a parent, such as asking questions or openly sharing with a parent. Negative engagement includes avoidance or negative reactions to talk (e.g., eye-rolling).

Most participants expressed positive engagement with talk, with some variation over time. For Time 1, 10 participants reported positive responses with parents about talk, while 12 participants reported positive engagement at Time 2 and 11 participants at Time 3. Across all three time points, examples of positive responses included asking questions related to sex and relationships or confiding in parents. Olivia described her openness with her mother at Time 1, "We were watching a movie once, and they said something about a booty call or something, and I asked her what it was, and she told me what it was," and how this openness changed when she was in high school, "I've always just asked my mom about questions. But it really—nothing really personal to myself, but then when I started to have sex, then I started to ask her more questions that were personal to myself." Lastly, Olivia described how she continues to talk with her mother as an emerging adult at Time 3, "I wouldn't really talk to her about like-like how you talk to your girlfriends about like, 'Oh, I just had this sex and it was amazing,' and stuff. Like I wouldn't do that. That's weird. But like (laughs) - if um - if I have a question or I felt weird or something like that, then I would tell her like, 'Oh, has this ever happened to you?' Or like um, 'This happened and I feel like-I don't know how I feel about it." ' Tony described his conversations with his mother at Time 1, "It was probably like a year ago when I started asking questions and talking about like (sex)-because I started seeing a lot of stuff on TV and they wanted to clarify it for me." At Time 2, he added, "She gives, like, good feedback. Um, like, she'll always give good feedback on what I say, or she'll always, um-I mean, she lets me finish when I'm talking, yeah." At Time 3, Tony described his process talking with his mother 
now that he is in a relationship, "She'll like ask how we're doing (him and his girlfriend) and stuff. But there's been like a couple of occasions where I've talked to her about it. I just really just listen and just tell her I am."

Negative engagement with talk seemed to show an increase over time with fewer participants describing negative engagement at Time 1 (4 participants) compared to Time 2 (10 participants) and Time 3 (9 participants). Across all three time points, negative engagement included teens' avoidance of some or all talk with parents about sex and relationships. For example, at Time 1 Sasha described why she avoids confiding in her mother, "Well, because sometimes my mom she like goes and tells everybody, and that gets me embarrassed. Because it's just between me and her." Sasha also reports avoidance of some conversations with her mother at Time 2, "It's just certain things I like keeping it to myself," and Time 3, "I just feel like that's like my personal business." Another teen, Steven Smith, discussed why he holds back from talking to his mother at Time 2, "I don't really like tell everything because, you know, she's my mom. So like I don't always tell her about, you know, girls I'm hanging out with or something," and at Time 3, "I will often withhold information just because like um it doesn't seem relevant or like I don't think she needs to know certain things." He added an example of his negative response to a conversation with his mother, "My mom then I guess kind of talked about like the orgasm disparity between women and men and how important it is to try and be conscious of that. But that was the extent of it because I asked her to stop talking."

\subsection{Talk about Dating and Relationships}

For the first content theme, talk about dating and relationships, responses included any reported talk about the teens' dating or relationships. This theme includes topics such as talk about participants' interest in or current dating or relationships, parent rules around dating or relationships, or teens friends' or family members' involvement in dating or relationships. Most participants described talk with parents about dating and relationships at Time 1 $(n=13)$, Time $2(n=11)$, and Time $3(n=14)$. At Time 1 , talk between teens and parents about dating and relationships often related to rules about dating and relationships. At Time 2, parents often shared advice about dating and relationships, including suggestions to delay dating. At Time 3, emerging adults described talk with parents focused on emerging adults' specific relationships such as checking in about them or asking questions about how their relationships were going. Parents also gave dating and relationship advice to their emerging adult children. One teen, Brittany, described her mother's rules at Time 1 about when it's acceptable to date, "She says around sixteen." Brittany's mother also gave her relationship advice at Time 2 "When I turned 15, she was like, 'Soon you're going to start dating but you have to be careful because like that person might not turn out who you want-like who you expected them to be and they can like hurt you like emotionally and physically.'" At Time 3, Brittany's mother asks about her current relationships, "She just does like an overall check-up, just making sure that like we're good, we have everything we need and stuff like that." Another teen, Sasha, described her mother's rules at Time 1 about when she was allowed to date, "She says when I'm in college, but .... I was like when I get to 10th, 11th, 12th, that's when I'll start." At Time 2, she described her mother's relationship advice "So the boy I kind of talk to now, she don't really like. So she just tells me all the time to not be with him. And I understand why she don't like him, because he's just like-I don't know, when he's with his friends he acts different." Sasha also talked about her mother's relationship advice at Time 3, "be with someone who has goals, who wants stuff in life, wants to be a successful person-you know, things like that."

\subsection{Talk about Pregnancy and Parenting}

The second content theme, talk about pregnancy and parenting, includes talk about pregnancy, preventing pregnancy, or preparing for or becoming a parent. Frequency of talking with parents about pregnancy and parenting was stable at Time 1 and Time 2 ( $n=12$, respectively), similar to Time $3(n=14)$. At all three time points, participants described 
talk with parents about delaying pregnancy and parenthood. Talk at Time 1 also included biology of pregnancy or childbirth. At Time 3, some conversations shifted to include future planning or exploration of parenthood. For example, Chris described how his mother talked with him at Time 1 about her own experience with pregnancy, "She told me like in the past how she went through it and stuff and that gave me knowledge about girls who get pregnant and what goes on." At Time 2, Chris' mother discussed why it's important to delay pregnancy, "She just gave an example like there's a couple of friends that I know and they're already pregnant at age $15 .$. then you're going to have one of your girlfriends walk around with your kid and you might not want that at a young age and they're miserable." For Time 3, Chris described his conversations with his mother about parenting, "it was just like one of those conversations where it just like comes up. I told her I didn't really want kids." Another teen who called herself Student described her conversations with her mother about delaying parenthood at Time 1, "(She) just don't want me to have like a guy that's not really like committed, kind of just wants to have a baby but not really like in the baby's life." At Time 2, Student describes her mother's messages about delaying pregnancy, "One time like when I first watched Teen Mom, I was just kind of confused of how like it happens and stuff. She was like letting me know like it's not something that like she would want for me." Lastly, at Time 3, Student talked about her conversations with her mother about parenthood, "I have like a lot of friends who still live at home and they like just recently had a kid. And so that's actually been like kind of like the common topic of conversation lately. She just wants us to be like stable and able to take care of ourselves on our own before we bring in like another child into the world."

\subsection{Talk about Protection}

For the third content theme, talk about protection, participants describe how they talk with their parents about protection, such as using condoms or other types or forms of protection, to protect from pregnancy or STIs. The majority of participants reported talk about protection at all three time points, with the lowest reported talk at Time 1 (Time 1, $n=9$; Time 2, $n=12$, Time 3, $n=11$ ). Messages about using protection were consistent over time and typically involved brief conversations where parents advised their children to use protection. For example, Olivia described how what she was learning in school sparked a conversation with her mother about protection, "I was like, 'Mom, did you know there were seventeen ways how to use a condom?' And she was like, 'No, there's not.' And I was like, 'Yeah, I learned it today." At Time 2, Olivia described her mother's messages about staying protected, "She tells me like, 'Be protected.'" At Time 3, Olivia and her mother discuss different forms of birth control and the importance of staying protected, "I tell her like when I don't like my birth control and when I'm going to switch it. Actually recently I talked to her about wanting to stop using birth control for a while since I've been on it for so long. And she was just like, 'You should make sure that you're protected, like using condoms if you're not going to use birth control." Another teen, Student, described her conversations with her mother about the importance of using protection at Time 1, "She just said like if I'm not sure if I want to have a kid at the time, then make sure it's protected." At Time 2, Student describes her mother's advice about the importance of staying protected, "She's like letting me know like um-like what can happen if someone does have like an STD or an STI and if I have sex with that person and it's unsafe, like what can happen to me and precautions I should take." At Time 3, Student describes how she can go to mother with questions about protection, "It comes up in conversation. Like I said, if like you have a question."

\subsection{Talk about STIs}

Participants described how they talk with their parents about STIs such as symptoms or types of STIs, importance of avoiding STIs and getting tested. Participants were less likely to describe talk with parents about STIs compared to other topics. At Time 1, 8 teens reported talking with parents about STIs, which dipped to two participants at Time 2, and 
was at 9 for Time 3. There were no clear thematic differences in talk about STIs across waves of data collection. Since so few teens reported talking about STIs at Time 2, the following example interview excerpts only include examples from Time 1 and Time 3. For example, Charles described how he talked about STIs with his father at Time 1, "Well my dad tells me like how they can come about, like liquid-like not liquid but like fluids like saliva and blood and whatever and how it can be transmitted and stuff." At Time 3, Charles describes how he and his father continue to talk about different types of STIs and their symptoms, "He always tells me about the different ones, like STI and STD's and the differences. You know, obviously we learned about that in school-how they can come about, you know, whether it's blood, physical interactions, and all this other stuff. And you know, what to look for on people, smells, you know, all that stuff you have to take into account." Another teen, Raven, described her conversations with her mother and stepfather about STIs at Time 1, "We talk about if I think something is wrong with me, I should tell them because it could spread. They talk about crabs and stuff." At Time 3, Raven described how her stepfather used photos of STIs to illustrate the importance of using protection, "There was a picture of like somebody—stuff that like (the infection?)—he'll be like, you know, 'This is why you should like use protection.' You know?"

\subsection{Talk about Sexual Behavior}

For the final content area, talk about sexual behavior, participants described how they talked with their parents about readiness for sex, reasons for delaying sex, and current or future sexual activity with a partner. At Time $1(n=12)$ and Time $2(n=13)$, most participants reported talk about this content area with parents, while fewer participants reported talk with their parents about sexual behavior at Time $3(n=5)$. At Time 1 and Time 2, teen-parent talk about sexual behavior typically related to delaying sex and reasons for delay. At Time 3, some emerging adults described why they talked less with parents about this topic. One teen, Steven Smith, described his mother's messages to him about readiness for sex at Time 1, "Well like they just say that I shouldn't have sex until like I'm really in love. They're not that strict with marriage because they're not religious" and at Time 2 he described a similar message from his mother, "She just says that um-that I have to be-like it's better if it's with somebody that you really know and that you really love and that it's always safe." At Time 3, Steven Smith discusses why he talks less with his mother about sex, "I'm in a relationship and she understands that I'm having sex. I'm assuming she assumes if I had any questions that I felt like she would be able to answer, that I would ask her. But otherwise uh I don't need to ask her. I don't know, she's not really like-like she's still my mom, but like in a lot of ways she doesn't play like the mother role as much anymore, just because I'm more independent now." Another teen, Tony, describes his parents' messages about delaying sex at Time 1 "They wanted me to be prepared and they wanted me to really be in love with the person and not just do it just to do it" and Time 2 he said of his mother, "She says if-well, the person that I have sex with first should be a person that I love." At Time 3, Tony described few conversations with his mother about sex, but also shared her ongoing advice about this issue, "It doesn't really come up like that much now because I'm in a relationship. She told me to never rush into it and make sure I know exactly-make sure I know like what the consequences are going to be. And also make sure that I know-well make sure I'm just not like abusing-well not really abusing, but I mean being out, just being promiscuous and stuff like that."

\subsection{Comparison of Gender across Time Points}

This section provides preliminary findings for the frequency of responses based on male and female teen/emerging adult participants. Given small numbers of male $(n=7)$ and female $(n=8)$ emerging adults in this sample, results address tendencies rather than statistical differences. For themes focused on experiences of family communication about sex, the number of participants who described expressed comfort/discomfort and positive engagement/negative engagement appeared to vary by gender across multiple time points 
(see Table 2). Specifically, female participants appeared more likely to report discomfort and disengagement in talk with parents about sex than male participants across all three time points. Interestingly, female participants also tended to report more positive engagement and more comfort than male participants, with the exception of comfort at Time 1 . Themes focused on the content of talk with parents showed more consistency than experience themes across male and female participants, with no clear patterns evident over time.

\section{Discussion}

This is the first qualitative study to longitudinally investigate youth perspectives on talk with parents about sex and relationships from early adolescence to emerging adulthood. Findings for talk about sex and relationships over time show that family talk about sexual issues goes beyond adolescence, but shifts in content to reflect changes in adolescent and emerging adult development. This study's findings fit with an understanding that emerging adulthood can entail connection and mutuality with parents, who continue to be key sources of support for their children [12]. This paper provides a unique exploration of the content and experiences of family talk about sex over the course of adolescence and emerging adulthood.

While parent-child communication continued from early adolescence to emerging adulthood, our findings suggest that this process is complex and that young people's experience of talk with parents varies over time. While participants' comfort and engagement with talking with parents about sex and relationships remained relatively constant (and high) over time, their expressed discomfort and disengagement appeared to increase, with many middle adolescent and emerging adult participants describing both positive and negative attitudes toward these conversations. Participants' responses suggest both a desire for parental connection and a need for privacy and independence, which fits with later stages of adolescent and emerging adult development [7]. Growing discomfort over time may also reflect a shift in conversations about sex and relationships from more hypothetical in early adolescence to more experience-based in middle adolescence and emerging adulthood, consistent with shifts toward involvement in relationships and sexual activity [6]. As adolescents become sexually active, they may become increasingly uneasy talking with parents about sex, as they may worry that their parents may be disappointed in them or judge their behavior $[15,16]$. A new scale which assesses openness in parent-teen talk about sex may provide opportunities to assess how the quality of parent-teen talk about sex relates to teens' sexual risk behaviors [32]. Our findings for older adolescents and emerging adults suggest that young people's comfort and engagement with talk may also vary with the content area as some participants identified topics that felt too personal or likely to generate family conflict. This interplay between connection and distancing makes parents' approaches to talking with their children about sex and relationships more difficult, as they may simultaneously experience their children as wanting to talk with them and pushing them away. This finding suggests a need for parents to be persistent and patient as they tolerate their children's shifting responses to family communication and seek opportunities to connect with their children about sex and relationship issues.

Most participants described ongoing talk with parents about dating and relationships and pregnancy and parenthood. However, participants' responses showed change in the content of these conversations over time. Talk about dating and relationships shifted from a focus on rules for dating to conversations about how emerging adults were doing in their relationships, with parental advice across all three time points. Similarly, talk about pregnancy and parenthood also showed continuity and change, with talk about delaying parenthood at all three time points, as well as changes from more concrete education (e.g., how someone gets pregnant) to conversations about future pregnancy and parenthood, consistent with changing needs and learning at each stage of development. Discussion of planning for parenthood was unique to emerging adulthood and has been little documented in prior research, which has focused more on parents' messages to their adolescent children about delaying sex and using protection (e.g., [24,33]). 
Protection and STIs were both consistently discussed over time, with fewer participants reporting talk about STIs than other sexual topics. Further, few participants described talk about STIs at Time 2, which is surprising, given most participants reported talk about protection at this time point. This lack of talk may reflect parents' heightened concerns about pregnancy compared to STI contraction at this stage of adolescents' development. The lack of family communication about STIs during middle adolescence is concerning. Accurate information about STIs may be critical at this time as over half of U.S. adolescents are sexually active by age 18 [34], with high rates of STIs among young people in the U.S. [8], accounting for half of all new cases.

For talk about sexual behavior, participants at Time 3 were less likely to describe family talk compared to the other two waves or to other sexual topics. While participants often described talk with parents during early and middle adolescence about delaying sexual behavior, participants in emerging adulthood identified this talk as no longer relevant, often due to their involvement in serious relationships or their sexual activity. This may be due to the focus of family talk about sex on delaying sex and negative consequences of sex [24,33], perhaps due to parents' fears that talking about the positive aspects of sex may encourage their sexual behavior $[17,35]$.

This study also explored gender variation in the perceptions and content of participants' family communication, which has been identified in multiple studies $[2,21,22]$. While differences in the content of talk were not evident across male and female participants, female participants appeared more likely than male participants to describe both positive and negative perceptions of talk with parents about sex and relationships. For example, while discomfort talking with parents seemed to increase over time for the overall sample, the numbers at each time point were higher for female than male participants. This may reflect higher involvement in talk with parents for females compared to male young people, which fits prior research that parents talk more about sexual issues with female teens than male teens [36]. Perhaps a higher level of communication and engagement overall creates more opportunities for both positive and negative interactions. It is interesting that there were not clear differences in the content of talk described by male and female participants, which counters studies that identify gender stereotypes in how parents talk with their sons and daughters about sex $[23,24]$. It may be that limitations of this small sample or a lack of follow-up questions about the content of talk within different topics in part explain this absence of findings.

This study provides new insights to continuity and change in the content and experiences of talk with parents about sex and relationships from adolescence to emerging adulthood. It adds to research documenting the parents' role as a supportive resource on sex and relationships extending beyond adolescence $[3,14,20]$ and suggests that families adapt their conversations to reflect changes in parent-child relationships from high parental authority in early adolescence [7] toward greater mutuality during emerging adulthood [12]. This study's findings reveal patterns of simultaneous positive and negative engagement in talk with parents about sexual issues, especially in middle adolescence and emerging adulthood, that highlight parents' opportunities and challenges in talking with their children about sex and relationships. These findings demonstrate the possibility for ongoing connection and communication with adolescents and emerging adult children and also explains some reasons why many parents experience roadblocks to talk with teens about these topics [33]. It also provides examples for how family talk about sex and relationships can evolve over time to adjust to adolescents' developmental stage and changing patterns of parent-child relationships.

This study is limited by its convenience sample, which largely consists of participants who have actively engaged in talking with their parents about sex and relationships. Participants were part of a comprehensive sex education program when they were early adolescents, which may have increased parent-child talk about sex and relationships. Future studies which track family talk about sex and relationships over time would be strengthened by the inclusion of families with less engagement in talk about sexual issues. 
This is a small sample, so results should be considered preliminary. However, the longitudinal data in this study are unique, investigating communication over eight years of adolescence and emerging adulthood, which contributes to existing research despite the small sample. Future research with larger samples would benefit from the exploration of sub-groups within the sample, such as those with varying religiosity and experiences of school-based sex education. An additional limitation is that data from some participants from our original sample were not included in the current analysis as it did not include interviews at all three time points, primarily due to changing contact information. In order to explore family communication longitudinally, only teens/emerging adults who completed all three waves of interviews were included in the current analysis. Low representation of fathers in this study is a further limitation. Research suggests that the gender of both parents and their children contribute to the content and impacts of family talk about sex [2,21,22], yet little research explores fathers' talk about sex with their sons or daughters [1,37]. Future studies would benefit from the exploration of fathers' talk with their same and different-gender children and its continuity and change over the course of adolescence and emerging adult development. While a strength of the current sample is it's racial/ethnic diversity, variation in family sexuality communication across racial and ethnic groups $[37,38]$ suggests the need for future research to investigate change in adolescents and emerging adults from different racial/ethnic groups over time. Larger samples are needed to assess the role of adolescents' and emerging adults' gender over time in talk with parents about sex and relationships. Quantitative studies are also needed to investigate whether conversations with parents about sex and relationships reduce risky sexual behaviors in emerging adulthood, as they have been shown to be protective in adolescence [1,2,39].

Parental conversations with early adolescents may lay the groundwork for talk about sex and relationships throughout young people's development and are recommended by the U.S. Department of Health and Human Services [40]. Parental practice talking with their early adolescent children about sex and relationships may help parents build a base of comfort and connection to navigate the challenges and opportunities for family talk about sexual issues during their children's middle adolescence and emerging adulthood. Most programmatic support for parents' talk with their children about sex and relationships focuses on early and middle adolescence [41,42]. Programmatic emphasis on the ongoing process of family communication and the need for parents to adapt talk with their children to fit their developmental stage could support parents' talk with their children into emerging adulthood.

\section{Conclusions}

This study gives a unique window into young people's experiences of talk with parents about sex and relationships from early adolescence to emerging adulthood. These findings underscore the ongoing and meaningful role parents can play in talk with their children about sexual issues. They also spotlight growing challenges that parents may face as their children develop and experience dual responses of valuing talk with parents about sex and relationships and increasing discomfort with some aspects of these conversations. Establishing open communication with children at an early age may help parents to continue these conversations throughout adolescents and into emerging adulthood. Parents' persistence and patience are needed to tolerate their children's shifting responses to family communication and find opportunities to connect with teens about sex and relationships. Programs can support parents by encouraging ongoing family communication over the course of development, providing tips to adapt parental responses to their children's developmental stage, and recognizing the ups and downs that may come as parents continue to engage with their children throughout their development. 
Author Contributions: Conceptualization, J.M.G. validation, J.M.G. and A.M.R. formal analysis, J.M.G. and A.M.R.; writing-original draft preparation, J.M.G. and A.M.R.; writing-review and editing, J.M.G. and A.M.R.; supervision, J.M.G.; project administration, A.M.R.; funding acquisition, J.M.G. All authors have read and agreed to the published version of the manuscript.

Funding: This research was funded by a grant from the Eunice Kennedy Shriver National Institute of Child Health and Human Development, grant number R03 HD095029-01A1.

Institutional Review Board Statement: The study was conducted according to the guidelines of the Declaration of Helsinki and approved by the Institutional Review Board of Wellesley College (7 August 2018).

Informed Consent Statement: Informed consent was obtained from all subjects involved in the study.

Data Availability Statement: The data presented in this study are available on request from the corresponding author. The data are not publicly available due to concerns about privacy of participants' responses.

Acknowledgments: The authors are grateful for the participants who shared their experiences and perspectives for this project.

Conflicts of Interest: The authors declare no conflict of interest. The funders had no role in the design of the study; in the collection, analyses, or interpretation of data; in the writing of the manuscript, or in the decision to publish the results.

\section{References}

1. Guilamo-Ramos, V.; Bouris, A.; Lee, J.; McCarthy, K.; Michael, S.L.; Pitt-Barnes, S.; Dittus, P. Paternal influences on adolescent sexual risk behaviors: A structured literature review. Pediatrics 2012, 130, 1313-1325. [CrossRef] [PubMed]

2. Widman, L.; Chukkas-Bradley, S.; Noar, S.M.; Nesi, J.; Garrett, K. Parent-Adolescent Sexual Communication and Adolescent Safer Sex Behavior: A Meta-Analysis. JAMA Pediatr. 2016, 170, 52-61. [CrossRef] [PubMed]

3. Fletcher, K.D.; Ward, L.M.; Thomas, K.; Foust, M.; Levin, D.; Trinh, S. Will it help? Identifying socialization discourses that promote sexual risk and sexual health among African American youth. J. Sex Res. 2015, 52, 199-212. [CrossRef] [PubMed]

4. Flores, D.D.; Meanly, S.P.; Wood, S.M.; Bauermeister, J.A. Family characteristics in sex communication and social support: Implications for emerging adult men who have sex with men's PrEP engagement. Arch. Sex. Behav. 2020, 49, 2145-2153. [CrossRef]

5. Arnett, J.J. Emerging adulthood: A theory of development from the late teens through the twenties. Am. Psychol. 2000, 55, 469-480. [CrossRef]

6. Kirby, D. Emerging Answers 2007: Research Findings on Programs to Reduce Teen Pregnancy and Sexually Transmitted Diseases; National Campaign to Prevent Teen and Unplanned Pregnancy: Washington, DC, USA, 2007.

7. Grotevant, H.D.; Cooper, C.R. Patterns of interaction in family relationships and the development of identity exploration in adolescence. Child Dev. 1985, 56, 415-428. [CrossRef]

8. Division of STD Prevention; National Center for HIV / AIDS; Viral Hepatitis; STD; TB Prevention; Centers for Disease Control and Prevention. National Overview of STDs. 2019. Available online: https://www.cdc.gov/std/statistics/2019/overview.htm\# Chlamydia (accessed on 14 December 2021).

9. Finer, L.B.; Zolna, M.R. Declines in Unintended Pregnancy in the United States, 2008-2011. N. Engl. J. Med. 2016, 374, 843-852. [CrossRef]

10. Lyons, H.A.; Manning, W.D.; Longmore, M.A.; Giordano, P.C. Gender and casual sexual activity from adolescence to emerging adulthood: Social and life course correlates. J. Sex Res. 2015, 52, 543-557. [CrossRef]

11. Caico, C. Sexually Risky Behavior in College-Aged Students. Open J. Prev. Med. 2014, 04, 354-364. [CrossRef]

12. Koepke, S.; Denissen, J.J.A. Dynamics of identity development and separation-individuation in parent-child relationships during adolescence and emerging adulthood-A conceptual integration. Dev. Rev. 2012, 32, 67-88. [CrossRef]

13. Monica McGoldrick, B.C.N.G.P. The Expanding Family Life Cycle: Individual, Family, and Social Perspectives, 5th ed.; Pearson: Boston, MA, USA, 2016.

14. Morgan, E.M.; Thorne, A.; Zurbriggen, E.L. A longitudinal study of conversations with parents about sex and dating during college. Dev. Psychol. 2010, 46, 139-150. [CrossRef] [PubMed]

15. Crohn, H.M. Communication about sexuality with mothers and stepmothers from the perspective of young adult daughters. $J$. Divorce Remarriage 2010, 51, 348-365. [CrossRef]

16. Golish, T.; Caughlin, J. "I'd rather not talk about it": Adolescents' and young adults' use of topic avoidance in stepfamilies. J. Appl. Commun. Res. 2002, 30, 78-106. [CrossRef]

17. Grossman, J.M.; Jenkins, L.J.; Richer, A.M. Parents' Perspectives on Family Sexuality Communication from Middle School to High School. Int. J. Environ. Res. Public Health 2018, 15, 107. [CrossRef] 
18. Grossman, J.M.; Richer, A.M. Parents' Perspectives on Talk with Their Adolescent and Emerging Adult Children About Sex: A Longitudinal Analysis. Sex. Res. Soc. Policy 2021, 1-14. [CrossRef]

19. Padilla-Walker, L.M. Longitudinal change in parent-adolescent communication about sexuality. J. Adolesc. Health 2018, 63, 753-758. [CrossRef]

20. Pariera, K.L.; Brody, E. 'Talk more about it': Emerging adults' attitudes about how and when parents should talk about sex. Sex. Res. Soc. Policy A J. NSRC 2018, 15, 219-229. [CrossRef]

21. Bulat, L.R.; Ajduković, M.; Ajduković, D. The role of parents and peers in understanding female adolescent sexuality-Testing perceived peer norms as mediators between some parental variables and sexuality. Sex Educ. 2016, 16, 455-470. [CrossRef]

22. Deutsch, A.R.; Crockett, L.J. Gender, generational status, and parent-adolescent sexual communication: Implications for Latino/a adolescent sexual behavior. J. Res. Adolesc. 2016, 26, 300-315. [CrossRef]

23. Heisler, J.M. They need to sow their wild oats: Mothers' recalled memorable messages to their emerging adult children regarding sexuality and dating. Emerg. Adulthood 2014, 2, 280-293. [CrossRef]

24. Manago, A.M.; Ward, L.M.; Aldana, A. The sexual experience of latino young adults in college and their perceptions of values about sex communicated by their parents and friends. Emerg. Adulthood 2015, 3, 14-23. [CrossRef]

25. Evans, R.; Widman, L.; Kamke, K.; Stewart, J.L. Gender differences in parents' communication with their adolescent children about sexual risk and sex-positive topics. J. Sex Res. 2020, 57, 177-188. [CrossRef] [PubMed]

26. Kuhle, B.X.; Melzer, D.K.; Cooper, C.A.; Merkle, A.J.; Pepe, N.A.; Ribanovic, A.; Verdesco, A.L.; Wettstein, T.L. The 'birds and the bees' differ for boys and girls: Sex differences in the nature of sex talks. Evol. Behav. Sci. 2015, 9, 107-115. [CrossRef]

27. Grossman, J.M.; Tracy, A.J.; Charmaraman, L.; Ceder, I.; Erkut, S. Protective Effects of Middle School Comprehensive Sex Education With Family Involvement. J. Sch. Health 2014, 84, 739-747. [CrossRef]

28. Lipstein, E.A.; Britto, M.T. Evolution of pediatric chronic disease treatment decisions: A qualitative, longitudinal view of parents decision-making process. Med. Decis. Mak. 2015, 35, 703-713. [CrossRef]

29. Patton, M.Q.P.M.Q. Qualitative Research and Evaluation Methods; Sage Publications: Thousand Oaks, CA, USA, 2002.

30. Miles, M.B.; Huberman, A.M. Qualitative Data Analysis: An Expanded Sourcebook, 2nd ed.; SAGE: Thousand Oaks, CA, USA, 1994.

31. QSR International. NVivo Qualitative Data Analysis Software; Version 10; QSR International: Melbourne, Australia, 2012.

32. Rogers, A.A.; Padilla-Walker, L.M.; Hurst, J.L. Development and testing of the Parent-Child Sex Communication Inventory: A multidimensional assessment tool for parent and adolescent informants. J. Sex Res. 2022, 59, 98-111. [CrossRef]

33. Elliott, S. Talking to Teens about Sex: Mothers Negotiate Resistance, Discomfort, and Ambivalence. Sex. Res. Soc. Policy 2010, 7 , 310-322. [CrossRef]

34. Centers for Disease Control and Prevention. Youth Risk Behavior Survey Data. 2017. Available online: www.cdc.gov/yrbs (accessed on 10 November 2021).

35. Pariera, K.L. Barriers and prompts to parent-child sexual communication. J. Fam. Commun. 2016, 16, 277-283. [CrossRef]

36. Kapungu, C.T.; Baptiste, D.; Holmbeck, G.; McBride, C.; Robinson-Brown, M.; Sturdivant, A.; Crown, L.; Paikoff, R. Beyond the 'birds and the bees': Gender differences in sex-related communication among urban African-American adolescents. Fam. Process 2010, 49, 251-264. [CrossRef]

37. Wright, P.J. Father-child sexual communication in the United States: A review and synthesis. J. Fam. Commun. 2009, 9, 233-250. [CrossRef]

38. Malacane, M.; Beckmeyer, J.J. A review of parent-based barriers to parent-adolescent communication about sex and sexuality: Implications for sex and family educators. Am. J. Sex. Educ. 2016, 11, 27-40. [CrossRef]

39. Bonafide, K.E.; Vanable, P.A.; Carey, M.P. The association between African American parent-child sex communication and adolescent condomless sex. AIDS Behav. 2020, 24, 847-853. [CrossRef]

40. Department of Health and Human Services. Talk to Your Kids about Sex. 2021. Available online: https://health.gov/ myhealthfinder/topics/everyday-healthy-living/sexual-health/talk-your-kids-about-sex\#panel-1 (accessed on 4 October 2021).

41. Marseille, E.; Mirzazadeh, A.; Biggs, M.A.; Miller, A.P.; Horvath, H.; Lightfoot, M.; Malekinejad, M.; Kahn, J.G. Effectiveness of school-based teen pregnancy prevention programs in the USA: A systematic review and meta-analysis. Prev. Sci. 2018, 19, 468-489. [CrossRef] [PubMed]

42. Santa Maria, D.; Markham, C.; Bluesman, S.; Mullen, P.D. Parent-based adolescent sexual health interventions and effect on communication outcomes: A systematic review and meta-analyses. Perspect. Sex. Reprod. Health 2015, 47, 37-50. [CrossRef] [PubMed] 